\title{
As africanidades e suas asperezas
}

\author{
Amaranta Cesar ${ }^{1}$ \\ Lúcia Ramos Monteiro ${ }^{2}$
}

${ }^{1}$ Amaranta Cesar é professora adjunta de Cinema e Audiovisual da Universidade Federal do Recôncavo da Bahia (UFRB). É doutora em Cinema e Audiovisual pela Universidade Sorbonne Nouvelle - Paris 3 (2008) e realizou estágio pós-doutoral na New York University. Foi curadora da Mostra 50 Anos de Cinema da África Francófona (Ano da França no Brasil, 2009). Idealizou e coordena o Cachoeiradoc - Festival de Documentários de Cachoeira (BA). Tem publicado artigos e capítulos de livros sobre cinemas africanos e das diásporas, cinema documental, cinema e diferenças culturais.

e-mail: amaranta.cesar@gmail.com

${ }^{2}$ Lúcia Ramos Monteiro realiza pesquisa de pós-doutorado junto à Escola de Comunicações e Artes da Universidade de São Paulo (ECA-USP) a respeito dos "Problemas contemporâneos para o conceito de cinema nacional", com financiamento da Fapesp. Ela é doutora em estudos cinematográficos pela Universidade Sorbonne Nouvelle - Paris 3 e pela USP (2014), com uma tese sobre "A iminência da catástrofe no cinema". Trabalhou como professora-visitante na Universidad de las Artes, em Guaiaquil, Equador, tendo dado aulas também na Paris 3 e na USP. Foi curadora da mostra África(s). Cinema e Revolução (Caixa

Belas Artes, 2016). e-mail: luciarmonteiro@gmail.com 
É possível enxergar contornos definidos naquilo que, no campo dos estudos de cinema, chamamos de "cinema africano"? A expressão designaria, em caso afirmativo, a reunião dos filmes realizados em África ou um conjunto de filmes feitos por africanos, dentro e fora dos limites do continente africano? A que público se destina esse "cinema africano"? Qual seria sua relação com os corpus e os conceitos encobertos pela etiqueta "cinema mundial"? Como pensar, a partir de um leque abrangente de filmes africanos, a ideia de "africanidade(s)", de identidade(s) africana(s) ou de identidade(s) cinematográfica(s) africana(s)? Impossível tentar responder a qualquer uma dessas interrogações sem aceitar o enfrentamento com um emaranhado de ambivalências e contradições.

O lugar que as africanidades ocupam no campo brasileiro das pesquisas e estudos em cinema é ainda difuso e espraia-se entre membros de uma pequena comunidade de pesquisadores, críticos e estudiosos de filiações e disciplinas diversas ${ }^{3}$. Em boa medida negligenciados pela história do cinema e praticamente ausentes das grades disciplinares dos cursos universitários, os filmes africanos constituem ainda objeto raro, corpus de difícil acesso no Brasil, apesar de esforços recentes para a sua difusão ${ }^{4}$. Distantes de possuírem uma

\footnotetext{
${ }^{3}$ Merecem destaque, dentre as publicações brasileiras que são referência na área, os volumes organizados por Alessandra Meleiro (2007), por Mahomed Bamba e Alessandra Meleiro (2012), e por Carolin Overhoff Ferreira (2014).

${ }^{4}$ Uma série de mostras e programações culturais têm surgido no Brasil em torno dos cinemas africanos. O evento mais constante dedicado à cinematografia do continente e de suas diásporas é, provavelmente, o Encontro de Cinema Negro, Brasil, África, e Caribe Zózimo Bulbul, que completa dez anos de existência em 2017. Idealizado pelo ator e realizador negro brasileiro Zózimo Bulbul, o encontro, que incorporou seu nome após seu falecimento em 2013, tem dinamizado o intercâmbio entre cineastas africanos, diaspóricos e afro-brasileiros e enfrentado o que parece se configurar como uma negligência crítica aos seus cinemas. Nesse sentido, é difícil não pensar na ausência da própria obra de Zózimo nas compilações clássicas da história do cinema brasileiro. Se Soleil ô (1970), o manifesto vanguardista e anticolonial de Med Hondo, ainda não encontrou lugar na história do cinema mundial compatível com a envergadura de sua invenção estética e discurso político, o mesmo se pode dizer de Alma no olho (1975), curta-metragem de Zózimo Bulbul, no que diz respeito ao cinema do Brasil.
} 
institucionalidade própria e de se estabelecerem como um domínio de limites claros, é na fluidez de suas fronteiras que os cinemas de Áfricas e de suas diásporas nos desafiam.

Os questionamentos acima são suscitados, sob distintas modalidades, por cada um dos textos do presente dossiê, que se constitui como uma homenagem ao estudioso dos cinemas africanos Mahomed Bamba (1967-2015): sete ensaios inéditos, que foram submetidos à avaliação cega por pareceristas gabaritados, mais um texto de Dudley Andrew publicado pela primeira vez em português, um ensaio escrito especialmente para a ocasião por Kenneth W. Harrow, além de uma entrevista com Flora Gomes, realizada por Jusciele de Oliveira.

Nascido na Costa do Marfim, Mahomed Bamba fixou-se por assim dizer no Brasil. Foi professor da Faculdade de Comunicação da Universidade Federal da Bahia (UFBA), onde também atuava como pesquisador do programa de PósGraduação em Comunicação e Culturas Contemporâneas. Com graduação em Letras pela Universidade Nacional de Abidjan, na Costa do Marfim, ele realizou mestrado em Linguística Geral e Semiótica na Universidade de São Paulo (USP, 1997), e doutorado em Cinema e Estética do Audiovisual, também na USP (2002). Em seu artigo "In the name of 'cinema action' and Third World: The intervention of foreign film-makers in Mozambican cinema in the 1970s and 1980s", ele afirma: "O desafio da liberdade não tem fronteira nem nacionalidade" (BAMBA, 2012, p. 173). Deslocada do contexto original e retida agora no espaço de sua ausência e pela narrativa de sua trajetória, essa afirmação parece nos dizer também do modo como desafiar as fronteiras consistiu para Bamba um princípio de vida, gesto fundamental de liberdade.

Nômade, homem do mundo, sujeito entre-lugares, como se autodefinia, ao enfrentar os dilemas entre a afirmação política da identidade original e os devires do desterro, bem como a vontade de superar o persistente binarismo entre tradição e modernidade que ocupa parte considerável do pensamento sobre os cinemas e as artes africanas de um modo geral, Bamba defendeu que "a modernidade do cineasta africano, como a dos intelectuais negros das diásporas 
e no ocidente, começa exatamente pela sua capacidade de ser ao mesmo tempo cineasta africano e cineasta do mundo"5. Tal posição limiar requer não apenas, em suas palavras, "um jogo de dupla-consciência" mas ainda "um equilibrismo entre expectativas divergentes entre os públicos africanos e do mundo" (BAMBA, 2009, p.184). Nesse sentido, a notável contribuição de Mahomed Bamba para os estudos dos cinemas africanos no Brasil diz respeito não apenas aos seus esforços em constituir a cinematografia do continente e de suas diásporas como objeto de investigação e análise mas também à sua disposição em tensionar, a partir de um entre-lugar assumido como posto privilegiado de pensamento, os modos de interação entre os filmes africanos, os pesquisadores e os públicos. Sua crítica ao que chamou de "culturalismo automático" (BAMBA, 2009), que considerava vigorar na análise de tais filmes, traduzia a sua intenção aguda de postular a emergência de múltiplas grades de leitura que permitissem a proliferação dos sentidos das obras, não obstante o reconhecimento de que estas estão invariavelmente ancoradas em seus contextos histórico-culturais: "todas as gerações de cineastas africanos apresentam em suas obras uma diversidade temática e estética e seus trabalhos são reveladores de uma descontinuidade nas respostas frente aos desafios políticos e sociais ao longo da história da África" (BAMBA, 2007, p.95). É, finalmente, na sua dedicação em expandir os quadros de recepção e crítica, em provocar os horizontes de expectativa dos públicos e em interrogar os desenhos curatoriais das mostras e festivais que sua mirada e contribuição para os cinemas africanos conecta-se às suas pesquisas no campo dos estudos de recepção, para o qual dedicou-se também de modo notável e atuante ${ }^{6}$.

\footnotetext{
${ }^{5}$ Em sua análise dos filmes de Férid Boughedir, é possível encontrar essa aliança de forças contraditórias na caracterização das personagens femininas de Halfaouine e Un été à la Goulette, em que "há, sem dúvida, imagem de uma mulher culturalmente marcada de determinada pela tradição árabe-muçulmana" e, ao mesmo tempo, "o espectador se depara também com as imagens de uma mulher que é simultaneamente oriental, mediterrânea, ocidental e, em definitivo, universal” (BAMBA, 2012, p. 287).

${ }^{6}$ Cf., a esse respeito, BAMBA, 2013a, 2013b, 2011.
} 
Concentremo-nos sobre a questão da identidade no cinema: somos capazes de enxergar traços de uma identidade continental comum, ou ela se conjugaria sobretudo em termos nacionais e regionais, movendo-se também historicamente? Se adotamos como parâmetro a idade das nações africanas independentes, de fato as cinematografias africanas inserem-se entre as mais jovens do mundo. Mas como estabelecer o(s) marco(s) de início? É mesmo o lançamento, em 1962, de Borrom Sarret (O Carroceiro), curta-metragem do senegalês Ousmane Sembène? Para além de toda a filmografia realizada em África durante o período colonial, por encomenda de autoridades coloniais, e que recentemente começa a atrair a atenção da academia (BLOOM, 2008; PIÇARRA, 2015; ANTONIO e PIÇARRA, 2013), e do olhar sobre os africanos enquanto objeto da curiosidade etnográfica, que Sembène critica em diálogo com Jean Rouch (ROUCH e SEMBÈNE, 1965), como encarar os filmes de ficção ou os registros documentais realizados por estrangeiros de diferentes nacionalidades em momentos de estreita colaboração com movimentos independentistas internacionalmente articulados, como o MPLA de Angola, o PAIGC da Guiné-Bissau e de Cabo Verde, e a Frelimo de Moçambique? ${ }^{7}$ Ainda com relação à fundação do que seria "o cinema africano", devemos levar em conta a realização, em 1955, de Afrique sur Seine, de Jacques Mélo Kane, Mamadou Sarr e Paulin Soumanou Vieyra, curta-metragem de produção francesa, rodado em Paris por três jovens africanos que propõem uma inversão da mirada etnográfica, colocando os europeus como objetos do olhar africano?

\footnotetext{
${ }^{7}$ Com relação à filmagem em apoio aos movimentos independentistas ou de registro das zonas libertadas, é preciso citar a filmografia de Sarah Maldoror, que realiza, ao longo da década de 1960, filmes de ficção no âmbito dos movimentos anti-coloniais da Guiné-Bissau e de Angola. Há ainda importantes filmagens por parte de Dragutin Popovic, Margaret Dickinson, Robert Van Lierop ou do grupo Cinéthique junto aos guerrilheiros moçambicanos (abordados por José de Sousa em seu texto no presente dossiê; cf. também ARENAS, 2017, e GRAY, 2016); e nos registros de José Massip, John Sheppard e Piero Nelli nas áreas libertadas da Guiné-Bissau (a que Cunha e Laranjeiro fazem referência, em artigo publicado no presente dossiê).
} 
Em lugar de fixar limites e definições identitárias, talvez seja mais proveitoso pensar em termos de conquistas sucessivas, ou de etapas na afirmação de identidades que são na realidade múltiplas e movediças. Se nos inspirarmos no pensamento do cineasta Flora Gomes, da Guiné-Bissau, expresso na delicada entrevista à pesquisadora Jusciele de Oliveira, podemos dizer que o cinema africano ainda não existe - sua criação dependeria de equipamentos e suportes de gravação feitos em África por e para africanos, que levem em conta, por exemplo, a cor da pele negra. No mesmo ano daquele que é visto como o mais importante marco inaugural dos cinemas africanos, ou seja, o lançamento de Borrom Sarret de Sembène, Jean Rouch, então o mais profícuo dos cineastas "não-africanos" dedicados a filmar em África ${ }^{8}$, e que segundo Sembène filmava os africanos "como insetos", reconhece os limites das produções coloniais, do ponto de vista exógeno, acenando para a necessidade da fundação de uma perspectiva cinematográfica propriamente africana: "o que quer que façamos, nós não seremos nunca africanos e os filmes que realizaremos serão sempre filmes africanos realizados por estrangeiros" (ROUCH e SEMBÈNE, 1965).

Com efeito, o cinema africano nasce marcado pelo engajamento na reconquista e na descolonização tanto das nações recém-libertas quanto das imagens da África, estas últimas entendidas como essenciais para a consolidação das primeiras. Nesse sentido, num primeiro momento, a reescritura da História colonial, bem como a superação da imagem de alteridade do Ocidente moderno e a defesa da autorrepresentação constituem-se como programas essenciais para as cinematografias africanas, amplamente disseminados nos cinemas das diásporas, incluindo o cinema negro brasileiro. Hoje, no contexto de novos flancos de disputas, qual seria a contemporaneidade de tais perspectivas estéticas e políticas?

Nota-se, portanto, desde a década de 1950 um esforço para inverter o olhar etnográfico, de modo que homens e mulheres africanas se tornem sujeitos - e não

\footnotetext{
${ }^{8}$ Cf., a esse respeito, BAMBA, 2009 a.
} 
mais objetos - do cinema. Tal busca inicial pela representatividade das identidades africanas no cinema permanece atual, conjugando-se de maneiras distintas nos textos aqui reunidos - em entrevista a Jusciele Oliveira, Flora Gomes expressa a necessidade do ver-se nas imagens audiovisuais, necessidade só raramente atendida no contexto da Guiné-Bissau, em que predomina uma televisão que difunde produtos audiovisuais vindos do exterior - e se complexifica em torno da ideia de "descolonização das mentes", formulada pelo queniano Ngugi wa Thiong'o (1986), romancista e teórico dos estudos pós-coloniais que é referência fundamental para os trabalhos que podem ser lidos a seguir.

De fato, a perspectiva pós-colonial perpassa todo o dossiê "Africanidades", evidenciando o ambivalente papel do hífen - curiosamente chamado, em francês, de "traço de união" -, que se interpõe entre o prefixo "pós" e o substantivo "colonial", a um só tempo unindo-os e separando-os. Assim, se por um lado a mirada pós-colonial marca as rupturas com o colonialismo - presentes na filmografia ligada às independências -, por outro lado ela também sinaliza que há permanências e, nesse sentido, dependência de vestígios que subsistem de relações coloniais oficialmente extintas. Roy Armes situa as origens dessa ambivalência no imediato pós-independência: apesar da emancipação política, não se alteram as fronteiras coloniais, estabelecidas em acordos europeus nos anos 1880 e 1990; novas elites ocupam postos antes exercidos pelo colonizador na política, na burocracia, na educação, etc.; as línguas dos colonizadores continuam em uso nos órgãos administrativos dos jovens países, assim como mantêm-se as capitais e a rede de infra-estrutura implantadas pela metrópole e características do "centralismo autocrático" próprio ao Estado colonial. 
mobilidade social, os cineastas africanos (...) estão totalmente envolvidos - em sua vida e sua obra - com as ambiguidades desse processo. De fato, com sua cultura bilíngue, seus títulos universitários (frequentemente de pós-graduação ou doutorado) e sua formação técnica no exterior, eles estão entre os membros mais brilhantes dessa elite" (ARMES, 2012).

Em seu artigo, que busca uma identidade comum ao cinema africano e aborda os esforços para o reconhecimento de tal identidade, Dudley Andrew cria uma constelação, reunindo filmes de Ousmane Sembène, Souleymane Cissé, Med Hondo, Flora Gomes e Djibril Diop Mambéty, num arco temporal que vai de 1969 (Mandat) até 1996 (Waati), para falar da identidade africana assentada sobre uma aliança de forças de direções opostas: a raiz do baobá e o vento do Sahel, o desejo de fixar-se e a vocação nômade. "Os cineastas africanos podem preferir a imagem do nômade, mas muitos parecem destinados a viver como migrantes, indo de festival em festival, de universidade em universidade, para apresentar sua obra", afirma. Mas como enraizar-se e afirmar a própria perspectiva quando ainda são patentes a dependência de economias estrangeiras para financiar a realização e a necessidade do aval de festivais para garantir alguma chance de distribuição?

É preciso interrogar as modalidades de recepção e as economias dos cinemas africanos. Esse questionamento, motor de trabalhos anteriores Kenneth W. Harrow (2013), está presente de maneira subjacente em seu texto que integra este dossiê, "Cinema africano: perturbando a ordem (cinemática mundial)". Nele, o autor joga luz sobre as asperezas que as experiências audiovisuais africanas trazem para a organização dos estudos cinematográficos e em particular para os estudos do cinema mundial. Ele se interessa em especial pelo papel de filmes feitos em vídeo, em mini-indústrias e estruturas mais ou menos caseiras que, a exemplo de Nollywood, acabam criando maneiras de financiamento próprias, independentes de ajudas externas, e conseguindo estabelecer canais criativos que garantem sua visibilidade junto a públicos locais. Essa seria a etapa mais atual do cinema africano, mas seus objetos ainda se constituem como problemas para os estudiosos do cinema, que não sabem como incluí-los em suas antologias e seus cursos - o que leva Harrow, provocativamente, a enxergá-los como lixo, 
como resíduos. Como analisar esteticamente filmes feitos de maneira quase amadorística, que não circulam pelos canais conhecidos e são ignorados pela crítica? O que significa a ausência do cinema de Nollywood nas antologias do cinema mundial e mesmo do cinema africano? Como definir qual cinema africano é legítimo ou pode ser legitimado pela crítica e pela academia? É por essa seara que Harrow nos enreda, num artigo que abala alguns dos mais estabelecidos alicerces nos estudos dos cinemas africanos, dentre os quais aqueles construídos por Manthia Diawara (1992; 2010) e por Dudley Andrew (2004).

O cenário atual que Harrow descreve configura-se, de certo modo, como uma nova atualização do objetivo de "filmar o povo e devolver a imagem ao povo", notório na fundação do cinema moçambicano, tema trabalhado por José de Sousa Miguel Lopes. Em seu texto, "Cinema de Moçambique no PósIndependência: uma trajetória", o autor estabelece um panorama amplo, reunindo diferentes gerações de cineastas, estrangeiros, moçambicanos e de identidades híbridas, que participaram da criação do cinema nacional a partir de 1975. A expressão do desejo de "filmar o povo e devolver a imagem ao povo" encontra eco em alguns dos termos usados por Godard em seu projeto de audiovisual jamais implantado no país, e na ideia de "inverter a direção do olhar". De acordo com a abordagem de José de Sousa M. Lopes, tal ambição é preponderante no cinema moçambicano dos anos que se seguem à independência, "um cinema de clara ação militante", mas se modula com o tempo, levando a um momento atual de "despartidarização desse cinema, sem que perdesse um comprometimento com as causas sociais e com o sentido crítico a elas ligado".

No artigo "Guiné-Bissau: do cinema de Estado ao cinema fora do Estado", Paulo Cunha e Catarina Laranjeiro experimentam um caminho metodológico interessante: eles incluem em sua cronologia do cinema bissau-guineense tanto filmes que antecedem a própria independência do país, em 1973, quanto o cinema mais atual, informal, que circula em pen-drives em mercados populares do país. Como se sabe, o cinema da Guiné-Bissau, em suas origens, distingue-se pela particularidade de, ao invés de inaugurar-se com filmes pós-independência 
feitos por cineastas estrangeiros (como é o caso, por exemplo, em Moçambique), contar com cineastas bissau-guineenses formados em Cuba e no Senegal por iniciativa de Amílcar Cabral.

\footnotetext{
"Apesar do elevado número de realizadores 'caça-revoluções' que estiveram na Guiné-Bissau nesse período histórico, Amílcar Cabral considerava que faltava a capacidade de os guineenses produzirem as suas próprias imagens e assim, simbolicamente, garantir a independência do gesto e do olhar e a possibilidade da construção de uma memória fílmica realizada pelos próprios guineenses" (CUNHA \& LARANJEIRO, 2017).
}

Se, depois de crises sucessivas, a produção atual da Guiné-Bissau ainda depende de auspícios externos, sobretudo portugueses, novos cineastas vêm despontando, interrogando as fronteiras entre o cinema amador e o profissional:

\begin{abstract}
"No caso concreto da Guiné-Bissau, um território onde a cultura cinematográfica mais canônica é praticamente inexistente (nem os filmes do próprio Flora Gomes são conhecidos pela generalidade da população), os jovens autodidatas inscrevem-se numa cultura visual muito pautada pela estética e narrativa da televisão, dos vídeos musicais e dos videojogos, conteúdos bem mais acessíveis à generalidade da população. Produzidos fora de qualquer forma institucionalizada, esses filmes são geralmente falados em dialetos autóctones e refletem questões atuais e muito pertinentes para as comunidades locais, o que thes confere um forte cunho identitário." (CUNHA \& LARANJEIRO, 2017).
\end{abstract}

Seja na Nigéria, na Guiné-Bissau, em Gana ou em outros países africanos, essas cinematografias emergentes, apoiadas na tecnologia do home-vídeo e na difusão por pen-drive ou internet vêm se constituindo como uma nova resposta a "uma reivindicação do direito de olhar, de narrar e de imaginar o mundo", luta iniciada por Afrique sur Seine, filme trabalhado por Marcelo R. S. Ribeiro no artigo "Cosmopoéticas da descolonização e do comum: inversão do olhar, retorno às origens e formas de relação com a terra nos cinemas africanos".

\footnotetext{
"Contra a visualidade associada à autoridade do olhar colonial e aos usos pedagógicos do cinema dela decorrentes, contra a interdição francesa que impedia africanos de filmarem em territórios coloniais, contra o humanismo racista que define o universalismo a que a França aspira como metrópole, Afrique sur Seine reivindica o
} 
direito de olhar as paisagens de Paris a partir de alguma memória da africanidade que se inscreve, na estética do filme, sob a forma de um contraponto musical associado ao passado e à experiência subjetiva que antecede a migração em direção à Europa - e de uma busca da africanidade presente na contemporaneidade do espaço metropolitano - a África no Sena, isto é, a comunidade difusa que surge dos movimentos migratórios, que nasce no exílio e que encontra sua terra possível, embora temporária, na condição comum de desterro" (RIBEIRO, 2017).

Em sua busca por estabelecer um quadro conceitual para uma história das formas de imaginação da descolonização e das relações com a terra nos cinemas africanos, Marcelo Ribeiro desenha uma sorte de cartografia da invenção de um olhar. E é na análise de $A$ vida sobre a terra (2000), filme de Adberrahmane Sissako, que se desvela, mais uma vez neste dossiê, uma dupla articulação fundamental: o que se inventa é "um olhar sobre si que é, igualmente, um olhar sobre o mundo" e "um olhar a partir da África que é, ao mesmo tempo, um olhar a partir do mundo" (RIBEIRO, 2017).

Esta dupla inscrição e perspectiva está no cerne da invenção formal e da imaginação política de Bamako (2006), outro filme de Abderrahmane Sissako, analisado por Roberta Veiga no artigo "Cindir a cena, partilhar o cinema: sobre Bamako, de Abderrahmane Sissako". Através de seu "tribunal imaginário", que põe lado a lado, em disputa judicial, os cidadãos do Mali e as grandes corporações financeiras mundiais, concedendo aos sujeitos africanos "o tempo da imagem e do verbo", Sissako "permite ao cinema escrever a história a contrapelo" e "reinventar a política", nas palavras da autora. A força do dispositivo posto em ação pelo filme, segundo ela, reside na sua "dupla face": ao pretender "expor a sutura" termina por "expor também a fratura", ou seja, "um dano fundamental, que ao recolocar a distância constituinte da relação entre mundos, não pretende solucioná-la, mas fazer participar da cena, tomar a palavra e exibir corpos e tradições de sujeitos esquecidos e apagados" (VEIGA, 2017).

Construir a própria cena para fazer conviver entre si as imagens dos cinemas de Áfricas e das diásporas, enfrentando a dependência econômica do olhar internacional e interrogando a perspectiva crítica universalista - heranças da 
empresa e do pensamento colonial -, é a missão assumida pelo FESPACO, o maior festival de cinema africano, realizado bienalmente em Ouagadougou, Burkina Faso, analisado neste dossiê por Maíra Zenun de Oliveira, a partir das contribuições conceituais da teoria decolonial. Em "Sobre a colonialidade do pensamento em imagens e a reinvenção da negritude no Fespaco: maior festival de cinema africano", a autora defende que o Fespaco é "festival-ritual" que se afirma enquanto espaço de confrontação do imaginário eurocêntrico sobre a África, que persiste como um "perverso e sólido legado afetivo e sensorial" do sistema colonial.

Escrito por Jusciele Oliviera, o artigo que conclui este dossiê, “'Eu não quero ter um mundo de uma cor só': trajetória, autoria e estilo nos filmes do cineasta Flora Gomes", concentra-se no percurso e nas características de estilo marcantes no cinema de Flora Gomes, um dos quatro jovens escolhidos por Amílcar Cabral para estudar cinema em Cuba e voltar à Guiné-Bissau a tempo de filmar sua independência. Com base em uma discussão teórica sobre autoria no cinema, em declarações do próprio cineasta e em breves análises dos filmes do cineasta, Oliveira identifica alguns elementos característicos do cinema de Gomes, elementos que parecem reeditar a tensão entre a raiz do baobá e os ventos do Sahel de que nos falava o texto de Dudley Andrew. Por um lado, há a afirmação reiterada do pertencimento ao país-natal, seja na diegese, pontuada por elementos históricos e personagens emblemáticos (a figura de Amílcar Cabral é recorrente), seja na sonoridade dos diálogos, quase sempre falados em kriol guineense, idioma escolhido também para os títulos (a exceção é seu filme mais recente, Republica di mininus, falado em inglês). Por outro lado, há a experiência da viagem, outra constante de sua filmografia, traduzida visualmente em planossequência arrebatadores. A aliança que Flora Gomes faz entre panafricanismo e afirmação da guineendade, assim como a vocação universal de algumas de suas fábulas só fazem tornar esse jogo de forças ainda mais complexo. "Os filmes do realizador guineense contam histórias locais com desdobramentos globais", afirma Oliveira, ao relembrar alguns dos temas eleitos por Gomes: trânsitos, 
música, mulher, criança, guerra, migração, tradição, modernidade, coletividade, ecologia...

Diante de tamanha riqueza de interesses e características, parece mesmo impossível a afirmação de uma identidade monolítica e fixa para um cinema africano no singular. Impossível, ainda, é realizar hoje uma reunião de reflexões a respeito dos cinemas africanos que não leve em conta aquilo que para Harrow são suas "asperezas", de algum modo presentes também sob a forma textual. As páginas a seguir constituem-se como convites reiterados para um mergulho em diferentes modalidades da articulação entre africanidades e cinema. Se sobram pontos de interrogação nessa jornada - e é bom que seja assim -, acreditamos que os trabalhos aqui reunidos contribuirão para não deixar dúvidas com relação à vastidão e à potência desse campo de estudos. Que novas pesquisas venham estreitar as relações entre os estudos cinematográficos brasileiros e as africanidades, colocando seus resíduos para dentro de campo.

\section{Referências Bibliográficas}

ANDREW, Dudley. "An Atlas of World Cinema", in Framework: The Journal of Cinema and Media, vol. 45, $\mathrm{n}^{\circ} 2$ (outono de 2004), pp. 9-23. Republicado em LIM, Song Hwee \& DENNISON, Stephanie (eds). Remapping world cinema: identity, culture and politics in film. Londres: Wallflower Press, 2005, pp. 19-29.

ARENAS, Fernando. África lusófona: além da independência. Trad. Cristiano Mazzei. São Paulo: Edusp, 2017 (no prelo).

ARMES, Roy. "O cinema africano ao norte e ao sul do Saara". In MELEIRO, Alessandra (org.). Cinema no mundo: indústria, política e mercado. São Paulo: Escrituras/Iniciativa Cultural, 2007. Disponível também em Afroscreen, 28 de agosto de 2012, http://www.buala.org/pt/afroscreen/o-cinema-africano-ao-nortee-ao-sul-do-saara-1-parte, último acesso 20 de janeiro de 2017.

BAMBA, Mahomed, e MELEIRO, Alessandra (orgs.). Filmes da África e das diásporas. Objetos de discursos. Salvador: Edufba, 2012.

BAMBA, Mahomed. A Recepção cinematográfica: teoria e estudos de casos. Salvador: Edufba, 2013. 
. "Os espaços de recepção transnacional dos filmes: propostas para uma abordagem semiopragmática". In: Crítica cultural (Critic), v. 8, n. 2, pp. 219-237, jul./dez. 2013.

"Do 'cinema com sotaque' e transnacional à recepção transcultural e diaspórica dos filmes”. Palíndromo (Online), v. 5, n 5; pp.165-195, 2011.

"Construção de uma narrativa de aprendizagem e mise-enscène do corpo feminino em Halfaouine e Un été à la Goulette (de Férid Boughedir). In: Bamba, M. e Meleiro, A., Filmes da África e das diásporas. Objetos de discursos. Salvador: Edufba, 2012, pp. 261-288.

"Jean Rouch: cineasta africanista?". Devires. Cinema e humanidades (UFMG), Dossiê: Jean Rouch I, v.6, n. 1, 2009, pp. 92-107.

. "Que modernidade para os cinemas africanos". In: FORUMDOC.BH.2009. $13^{\circ}$ Festival do Filme Documentário e Etnográfico -Fórum de Antropologia, cinema e vídeo, 2009, Belo Horizonte. Catálogo do EventoFestival. Belo Horizonte, 2009. pp. 190-193.

"In the name of 'cinema action' and Third World: The intervention of foreign film-makers in Mozambican cinema in the 1970s and 1980s". Journal of African Cinemas, v. 3, p. 173-185, 2012.

BLOOM, Peter J. French colonial documentary. Mythologies of humanitarism. Minneapolis: University of Minnesota Press, 2008.

DIAWARA, Manthia. African film: new forms of aesthetics and politics. Nova York: Prestel, 2010.

Indiana University Press, 1992.

African cinema: politics and culture. Bloomington:

GRAY, Ros. "Já ouviu falar de internacionalismo? As amizades socialistas do cinema moçambicano". In Lúcia Ramos Monteiro (org.). África(s). Cinema e revolução (catálogo). São Paulo: Buena Onda, 2016, pp. 35-65, disponível em mostraafricas.com, último acesso 20 de janeiro de 2017.

HARROW, Kenneth W. Trash: African cinema from below. Bloomington: Indiana University Press, 2013.

MELEIRO, Alessandra (org.). Cinema no mundo: indústria, política e mercado. São Paulo: Escrituras/Iniciativa Cultural, 2007. 
